\title{
The Baseline Serum IgG4/IgG3 Ratio Might be a Suitable Marker for Predicting Favorable Treatment Response in Patients With Idiopathic Retroperitoneal Fibrosis-associated Hydronephrosis
}

\author{
Seung-Ki Kwok, M.D., Ph.D. \\ Division of Rheumatology, Department of Internal Medicine, Seoul St. Mary's Hospital, College of Medicine, The Catholic University of Korea, \\ Seoul, Korea
}

Retroperitoneal fibrosis (RPF) is a rare disease featuring the proliferation of fibrous tissue in the retroperitoneum, the compartment of the body containing the kidneys, aorta, renal tract, and various other structures. It may present with lower back pain, kidney failure, hypertension, deep vein thrombosis, and other obstructive symptoms [1]. Ureteral involvement has been reported in $80 \%$ $100 \%$ of the cases at presentation, occasionally causing hydronephrosis [2]. Hydronephrosis is a common complication of RPF and it may lead to poor outcome without appropriate intervention. RPF is categorized as secondary or idiopathic causes [3]. Secondary causes of RPF include infection, drug use, malignancy, radiation therapy and abdominal operation. Idiopathic RPF (iRPF) accounts for two-thirds of the RPF cases and can be divided into two groups: IgG4-related RPF and non-IgG4-related RPF [4]. Histologic confirmation would be great to diagnose IgG4-related RPF because treatment strategy for IgG4 related disease is well-defined. However, when we manage the patients with RPF in real clinical practice, it is very difficult to obtain sufficient tissues owing to the location of fibrosis and high risks associated with open biopsy. In addition, there have been no validated clinical parameters for assessing outcome of iRPF [5-7].

A recent paper by Choi et al. [8] published in Journal of Rheumatic Diseases investigated for the first time the predictive factors for hydronephrosis-associated outcomes among iRPF patients using clinical profiles and serum
IgG subclasses. They retrospectively included $18 \mathrm{iRPF}$ patients with hydronephrosis. Hydronephrosis improvement was assessed by image taken 6 months after diagnosis. On follow-up images, 8 patients (44.4\%) showed improvement in hydronephrosis. Patients with improvement more frequently had reverse serum IgG4/IgG ratio ( $87.5 \%$ vs. $30 \%, \mathrm{p}=0.025$ ), abdominal aorta involvement $(87.5 \%$ vs. $30 \%, \mathrm{p}=0.025)$ and glucocorticoid treatment ( $87.5 \%$ vs. $30 \%, p=0.025)$ than those without improvement. The proportion of elevated serum IgG4 level did not differ between the two groups. Interestingly, even in the 14 cases with normal serum IgG4 levels, it was found that reverse serum IgG4/IgG3 ratio was more frequent in patients with improvement than in those without improvement $(83.3 \%$ vs. $12.5 \%, \mathrm{p}=0.026)$. So, Choi et al. [8] could draw a conclusion that baseline serum IgG4/ IgG3 ratio might be a suitable serologic marker for predicting good treatment response in iRPF patients with hydronephrosis.

The study by Choi et al. [8] has two major limitations. One is the limited number of cases that was far from the strong statistical power. The other is the fact that tissue biopsy was not performed in all the cases. Nevertheless, clinical predictor for favorable hydronephrosis-associated outcomes in itself might be invaluable in that there been no validated clinical parameters for assessing outcome of iRPF. Thus, the rheumatologists could consider the application of baseline serum IgG4/IgG3 ratio as predictor for

Received : March 8, 2021, Revised : March 10, 2021, Accepted : March 10, 2021

Corresponding to : Seung-Ki Kwok iD http://orcid.org/0000-0002-6142-8364

Division of Rheumatology, Department of Internal Medicine, Seoul St. Mary's Hospital, College of Medicine, The Catholic University of Korea, 222 Banpo-daero, Seocho-gu, Seoul 06591, Korea. E-mail : seungki73@catholic.ac.kr

Copyright (c) 2021 by The Korean College of Rheumatology.

This is an Open Access article, which permits unrestricted non-commerical use, distribution, and reproduction in any medium, provided the original work is properly cited. 
favorable response of hydronephrosis when managing the iRPF patients.

\section{CONFLICT OF INTEREST}

No potential conflict of interest relevant to this article was reported.

\section{REFERENCES}

1. Vaglio A, Salvarani C, Buzio C. Retroperitoneal fibrosis. Lancet 2006;367:241-51.

2. Baker LR, Mallinson WJ, Gregory MC, Menzies EA, Cattell WR, Whitfield $\mathrm{HN}$, et al. Idiopathic retroperitoneal fibrosis. A retrospective analysis of 60 cases. Br J Urol 1987;60: 497-503.

3. Vaglio A, Maritati F. Idiopathic retroperitoneal fibrosis. J
Am Soc Nephrol 2016;27:1880-9.

4. Khosroshahi A, Carruthers MN, Stone JH, Shinagare S, Sainani N, Hasserjian RP, et al. Rethinking Ormond's disease: "idiopathic" retroperitoneal fibrosis in the era of IgG4related disease. Medicine (Baltimore) 2013;92:82-91.

5. Magrey MN, Husni ME, Kushner I, Calabrese LH. Do acute-phase reactants predict response to glucocorticoid therapy in retroperitoneal fibrosis? Arthritis Rheum 2009; 61:674-9.

6. Pelkmans LG, Aarnoudse AJ, Hendriksz TR, van Bommel $\mathrm{EF}$. Value of acute-phase reactants in monitoring disease activity and treatment response in idiopathic retroperitoneal fibrosis. Nephrol Dial Transplant 2012;27:2819-25.

7. Zhao J, Li J, Zhang Z. Long-term outcomes and predictors of a large cohort of idiopathic retroperitoneal fibrosis patients: a retrospective study. Scand J Rheumatol 2019;48:239-45.

8. Choi SJ, Oh JS, Hong S, Lee CK, Yoo B, Hong B, et al. Treatment response to idiopathic retroperitoneal fibrosis-associated hydronephrosis with a focus on IgG4/IgG3 serum concentration ratio. J Rheum Dis 2021;28:38-44. 